\title{
Post pandemia, los movimientos de la sociedad y la autoridad pública social en el Perú
}

\author{
Post pandemic, the movements of society and public social authority in \\ Peru
}

\section{Pós-pandemia, movimentos da sociedade e poder público social no Peru \\ Carolina Ortiz Fernández}

Universidad Nacional Mayor de San Marcos

cortizf@unmsm.edu.pe

https://orcid.org/0000-0002-6464-4652

\begin{abstract}
RESUMEN
En el presente trabajo, se explora algunos de los factores por los cuales, una significativa parte de la población trabajadora no acató el confinamiento social decretado tempranamente en el Perú. En segundo lugar, se indaga de manera introductoria las alternativas que se gestan y ofrecen desde las organizaciones sociales y los movimientos de la sociedad, en un contexto post covid, en el que con el discurso de la reactivación económica las elites tienden a profundizar la precarización del trabajo, el incremento de la mano de obra marginalizada y la creciente vigilancia autoritaria, como parte de la política global, que en el país no es reciente, existe desde hace varios años. Todo estas fuerzas en movimiento suponen un pachacuti, es decir una mutación radical. La pesquisa se aborda desde la des/ colonialidad del poder y la perspectiva de género.
\end{abstract}

\begin{abstract}
This paper explores some of the factors for which a significant part of the working population did not abide by the social confinement decreed early in Peru. Secondly, the alternatives that are created and offered from social organizations and society movements are investigated in an introductory way, in a post-covid context, in which with the discourse of economic reactivation the elites tend to deepen the precariousness of work, the increase in the marginalized workforce and the growing authoritarian vigilance, as part of global politics, and which in the country is not recent, has existed for several years. All these moving forces suppose a pachacuti, that is to say a radical mutation. A research is approached from the decoloniality of power and gender perspectiva.
\end{abstract}

\section{RESUMO}

No presente trabalho, são explorados alguns dos fatores pelos quais uma parte significativa da população trabalhadora não cumpriu o confinamento social decretado no início do Peru. Em segundo lugar, as alternativas que são gestadas e oferecidas por organizações sociais e movimentos sociais são investigadas de forma introdutória, em um contexto pós-cobiçado, em que com o discurso da reativação econômica, as elites tendem a aprofundar a precariedade do trabalho, o aumento da

Ortiz, C. (2020). Post pandemia, los movimientos de la sociedad y la autoridad pública social en el Perú. Espiral, revista de geografías y ciencias sociales, 2(4), 091 - 106. http://dx.doi.org/10.15381/espiral.v2i4.19536 
força de trabalho marginalizada e a crescente vigilância autoritária, como parte da política global, que no país não é recente, já existe há vários anos. Todas essas forças em movimento supõem um pachacuti, isto é, uma mutação radical. A pesquisa é abordada a partir da des/colonialidade do poder e da perspectiva de gênero.

PALABRAS CLAVES: Post pandemia; pachacuti; movimientos de la sociedad; autoridad pública social; descolonialidad del poder.

KEYWORDS: Post pandemic; pachacuti; movements of society; public social authority; decoloniality of power.

PALAVRAS CHAVES: Pós-pandemia; pachacuti; movimentos da sociedade; poder público social; descolonialidade do poder.

\section{Introducción}

El mundo ha perdido hace mucho la armonía. El tiempo lineal y progresivo de la modernidad parece derrumbarse en la versión desarrollista del neoliberalismo y la sociedad de consumo. Las promesas de la modernidad y su racionalidad instrumental han llegado a sus límites.

Durante el proceso colonial y en casi 200 años de república, la mayor parte de la población de nuestra América ha aprendido a supervivir en un continuo estado de riesgo y muerte. La presencia arrasadora de la pandemia está develando crudamente el patrón global de poder y su colonialidad encarnado en el control de los cuerpos humanos y no humanos, mediante las biopolíticas sanitarias, financieras, ambientales, agroindustriales, extractivistas, comunicacionales y culturales que recaen peligrosamente en la especie humana y nuestra casa mayor el planeta en su conjunto.

La estructuración histórica del orden social según las necesidades y dispositivos de la economía mundo del bloque global de poder que se organiza mediante la relación entre capitalismo y patriarcado, establecen las condiciones bajo las cuales pueden ejercer el derecho de subyugar, eliminar o matar al adversario o al que molesta, lo cual comprende a su vez la sujeción sexista de las mujeres, de la población trabajadora y de la Naturaleza; mientras que el racismo subyuga, discrimina, mata y /o elimina al que es diferente por considerarlo inferior física e intelectualmente.

Capitalismo, racismo y patriarcalismo son interdependientes y se retroalimetan. Generan una atmósfera de violencia que asfixia la vida mediante políticas económicas que resguardan la reconcentración de la riqueza de una minoría, las políticas de salud que hacen de ésta una mercancía, las políticas educativas que han promovido y promueven el etnocidio cultural desconociendo las condiciones de vida y las prácticas culturales de la población originaria, las biopolíticas que incentivan la destrucción de los ecosistemas al no respetar la consulta previa a los pueblos indígenas, dispuesta incluso por las organizaciones internacionales; el asesinato de sus liderezas y lideres, las políticas de población y de reproducción natal que niega los derechos sexuales y reproductivos, el hecho de exponer a la expulsión y la indigencia a una inmensa población que ya no es un ejército industrial de reserva como en la época de Marx sino mano de obra marginalizada (Quijano, 1996), masa marginal (Nun, 1969) cuya tendencia es a incrementarse.

Con todo, la resistencia se ha dado todo el tiempo. En la últimas décadas, la emergencia en la escena pública de los pueblos y nacionalidades indígenas, de los movimientos feministas y de las comunidades disidentes, de los movimientos populares y ecoambientales, movimientos de envergadura, han comenzado a develar la complejidad del poder. 
El poder global y su colonialidad pueden ser tolerantes a la multiculturalidad, al feminismo liberal a la diversidad sexual; pero totalmente intolerantes cuando se toca las fibras de la complejidad del poder y se logra desanudar el mello de acumulación sin fin y el conjunto de instituciones y relaciones ecopolíticas, de género, racializados, socioeconómicos que lo sostienen. Es allí cuando revive con mayor fuerza el orden social totalitario, el conservadurismo, la militarización, la naturalización de la muerte, el terror, la vigilancia, con la consiguiente pérdida de soberanía del individuo que se esconde en la apariencia de libre consumidor enarbolado por el American way of life que se globalizó con el neoliberalismo.

El combate a la pandemia global se torna propicio para impulsar una abrumadora vigilancia totalitaria de la que hacía referencia tempranamente la autora de Orígenes del totalitarismo (Arendt, 2011), en la que el despliegue del miedo, el terror y la tecnología se convierten en abrumadoras armas que pueden paralizar la energía de los movimientos de la sociedad, a no ser que estos las reviertan fortaleciendo sus organizaciones, sus prácticas y formas de vida alternativas. Para otros, supone la recuperación de la aplicación de políticas sociales y públicas, en un marco liberal progresista y neoliberal que continúa expoliando y destruyendo el ambiente y la vida.

En las últimas décadas, no ha habido diferencias sustanciales entre los gobiernos de derecha y de izquierda, en tanto aplicaron el mismo modelo económico al apoyar los sistemas financieros, los agronegocios, la política extractivista, los sistemas previsionales, que afectan a la población y a la Naturaleza. Si alguno pretendió la estatización de algunos sectores, lo hizo pero bajo los principios del modelo neoliberal. Los gobiernos neoliberales en el Perú, desde el fujimorismo, convocaron a algunos izquierdistas para integrar el gabinete ministerial en las áreas sociales, a fin de que se encarguen de administrar la precariedad de los servicios públicos sin cambios radicales.

Con el discurso del éxito y el emprendedurismo difundido por los espacios de información y comunicación, la mercantilización de la educación, de la salud y el extractivismo, sujetos a los mecanismos del desarrollismo neoliberal, lograron crear la ilusión de que somos consumidores y ciudadanos libres, contribuyendo de este modo a formar técnicos que destruyen con mayor celeridad la vida y la Naturaleza en su conjunto.

En la región latinoamericana, la pandemia viene afrontándose por un lado mediante el creciente autoritarismo, la militarización, la corrupción, el conservadurismo a nivel gubernamental y, por el otro, mediante políticas sociales.

En este marco, en lo que sigue, desde la perspectiva teórica de la des/colonialidad del poder y de género, se explora algunos de los factores por los cuales, una significativa parte de la población trabajadora no acató el confinamiento social decretado tempranamente en el Perú. En segundo lugar, se explora las alternativas que se gestan $\mathrm{y}$ ofrecen desde las organizaciones sociales y los movimientos de la sociedad que abren la posibilidad de articular una autoridad pública social en un contexto post covid. Con el discurso de la reactivación económica, las elites tienden a profundizar la precarización del trabajo, el control de la población trabajadora, a incrementar de la mano de obra marginalizada y la creciente vigilancia autoritaria que, no es reciente, existe en el país desde hace varios años sobre todo en algunas medianas y grandes empresas, en el sistema financiero y en algunos centros privados del campo del saber. Todo estas fuerzas en movimiento parecen anunciar una mutación radical, es decir un pachacuti, ${ }^{1}$ un mundo al revés, semejante al acontecimiento ocurrido con la llegada

1 En diciembre del 2019, en la mesa redonda << Los avances en la descolonialidad del poder en América Latina >> , llevada a cabo en el XXXII Congreso de la Asociación Latinoamericana de Sociología en la UNMSM, señalábamos que nuestra América estaba siendo sacudida por un pachacuti, porque venía ocurriendo una gran mutación impulsada desde los movimientos de la sociedad. Ahora podemos decir que no es solo nuestro continente sino el planeta entero. Esta mutación puede conducirnos a algo mejor o peor, no lo sabemos, todo depende de lo que hagamos o dejemos de hacer. 
de los "españas", tal como lo concibió Felipe Guaman Poma en la Nueva coronica y buen gobierno. (Ortiz, 2009). Esta vez, la concepción lineal y progresiva del mundo tiende derrumbarse.

\section{Estado de emergencia nacional en Perú y el confinamiento social}

En el Perú, el gobierno del presidente Martín Vizcarra Cornejo emitió el decreto supremo No 044 -2020-PCM, que declaró el Estado de Emergencia Nacional que habilitó la cuarentena a partir del 16 de marzo ante "las graves circunstancias que afectan la vida de la Nación a consecuencia del brote del COVID-19" (Decreto Supremo, 2020). Paulatinamente, dispuso un conjunto de políticas sociales a fin de afrontar la pandemia y el trágico sistema de salud pública, pero sin un conocimiento cabal de la situación real en que vive la población trabajadora y sin un conocimiento de la heterogeneidad histórico estructural del país, de la heterogeneidad sociocultural y territorial.

A nivel laboral, el Ministerio de Trabajo y Promoción del Empleo en el Perú emitió el Decreto de Urgencia $N^{\circ}$ 038-2020, mediante el cual se aprobó la suspensión perfecta de labores. El desempleo que el 2019 tuvo un promedio de 6.1\%, en junio del 2020 llegó al 16.4 \% . En Lima, la población económicamente no activa asciende a 3’436,000 (INEI, 2020). A lo que se añade el éxodo de más de 300,000 trabajadores a sus pueblos de origen.

En relación al campo laboral, es necesario tener presente que en el Perú el empleo es precario y eventual, y que más del 70 \% de la población peruana forma parte de lo que comúnmente se denomina sector informal y de las actividades marginalizadas de la economía. Este sector que se caracteriza por su heterogeneidad (formado por el pequeño comercio, por unidades económicas populares, artesanales, comunitarias y pequeñas empresas articuladas por el capitalismo) no es posible explicarlo como una simple falta de adecuación de las normas. Como sabemos, hoy en día, las corporaciones requieren menos fuerza de trabajo directamente empleado debido a que la mano de obra, es reemplazada por el trabajo acumulado que se concentra en la alta tecnología (Quijano, 1996), de allí la urgencia de la población de crear diversos mecanismos de supervivencia que se apoyan en lo que se denomina eufemísticamente autoempleo, la economía familiar, de parentesco o paisanaje mediante la ayuda mutua y la reciprocidad, que son algunos de los principios de la organización comunitaria en intenso conflicto e interdependencia con el individualismo moderno colonial sujeto al patrón global de poder.

Las grandes corporaciones promueven y hacen uso de la economía informal y de las actividades marginalizadas, se sostienen en ellas de manera muy favorable en tanto ahorran costos y derechos laborales. Los sectores populares, los pueblos y nacionalidades indígenas y las mujeres sobre todo provenientes de estos sectores se encuentran inmersos en esta dinámica. Por eso, la vida de los hogares de la población trabajadora depende de lo que se comercializa cada día sobre todo en los mercados populares y en el mercadeo ambulatorio o desde su casa taller, si no comercializa sus productos muere de hambre. Vale precisar que las corporaciones mineras, que constituyen la maquinaria más depredadora del hábitat en su conjunto incluido los humanos, no han detenido sus actividades.

\section{El resquebrajamiento del discurso del estado nación moderno}

En la televisión peruana, los spots oficiales llaman a la unión nacional. El presidente Vizcarra con un discurso ilocutivo ${ }^{2}$ (Austin, 1970) que convoca a la unión: "Somos un solo país, debemos estar unidos para vencer la guerra contra el covid 19" (Vizcarra, 2020).

2 ilocutivo, en términos de Austin, implica que el emisor de un discurso llama, a sus oyentes y lectores, a la acción. 
¿Cómo lograr la unidad si no se conoce ni comprende la heterogeneidad histórico estructural, la heterogeneidad sociocultural y ecoterritorial del país?

Desde las elites económicas y políticas se continúa predicando la ilusión de que somos un estado nación donde todos somos iguales, un espejo distorsionado que se resquebraja violentamente en estos días de dolor y sufrimiento.Ya no es posible negar lo evidente.

La vida republicana próxima al bicentenario no ha cambiado mucho las pésimas condiciones de vida de la mayoría de la población, a pesar de que en las últimas décadas cada gobernante se vanagloriaba de estar próximos al primer mundo.

Por eso, es una impostura, pensar que la solución es exclusivamente la guerra contra el nuevo coronavirus, porque lo que está matando son las prácticas destructivas del capitalismo, el racismo y el patriarcalismo avalados por el estado nación, el covid 19 no es más que la creación de su propia contradicción a partir de la nefasta concepción de desarrollo en el Perú y el mundo, y lo gravísimo es que no será la única pandemia si no se cambia drásticamente la forma de vida neoliberal y el patrón global de poder.

Por otro lado, vale mencionar que la aprobación del presidente Vizcarra se basa en la autoridad paterna tutelar que busca orientar la vida de la población peruana. Es la primera vez que se escucha una voz que se dirige al país de manera respetuosa. En las redes virtuales, numerosos adeptos han afirmado: "es como escuchar a mi papá". Se podría decir que en muchos casos mostró su disposición a escuchar las demandas de la población, pero esta escucha se queda corta ante la política económica que su gobierno defiende y el eurocentrismo y racismo que coloniza el imaginario de la mayor parte de los grupos de poder. En junio se destinó, aproximadamente, 265 millones de dólares a las compañías más poderosas; mientras que a la población trabajadora se le destinó apenas 26,000 millones de dólares. El gobierno no aceptó gravar impuestos directos a la riqueza. Estas decisiones gubernamentales continúan contribuyendo a reconcentrar la riqueza en unos pocos, a incrementar el desempleo y el malestar de la población, con la consiguiente profundización de las desigualdades. En los 90, los fundamentalistas del mercado liderados por el fujimorismo se oponían a la intervención del estado, en los últimos años lo reclaman como ente regulador.

\section{El discurso sanitario y el racismo}

El discurso sanitario que ha circulado oficialmente por la prensa, la radio, las redes, exige limpieza, pero al ignorar las condiciones reales en que vive y labora la mayor parte de la población, en tanto numerosas viviendas y centros de trabajo precarios carecen de un debido acondicionamiento de agua y desagüe, resultan vacíos. Apremia que la formación profesional establezca una ruptura con el eurocentrismo y el racismo epistémico a fin de conectar con la realidad peruana, de lo contrario continuará siendo recurrente que médicos y personal sanitario en general, funcionarios y un sector no desdeñable de la población catalogue de sucios e ignorantes a la población trabajadora y a sus mecanismos de intercambio.

Numerosas personas han señalado en diversas instancias y en las redes que vivimos en un país infantil, que no sabe lo que es la higiene y hace lo que quiere, que por culpa de esta gente no se logra vencer al nuevo coronovirus. Estas calificaciones racistas revelan que no se comprende las diferenciación social y las desigualdades existentes, reiteran el desconocimiento de las condiciones de vida de la gran mayoría de la población trabajadora. En Perú, no es el covid el que mata, sino las profundas desigualdades, la reconcentración de la riqueza, el capitalismo, el patriarcalismo y el racismo del patrón global de poder.

En numerosos casos, lejos de apoyarlos, el discurso sanitario ha demonizado los mercados populares, sobre todo desde la prensa y los programas televisivos favorables 
a las corporaciones. Se olvida que el virus llegó al Perú a través de los sectores medios y altos, y que numerosos trabajadores de las cadenas de supermercados también adquirieron el nuevo coronavirus, pero estos lugares fueron atendidos antes que los mercados de barrios, usualmente conformados por comerciantes provenientes de la mano de obra marginalizada. Recordemos que estos centros de intercambio comercial popular, en su mayoría, han sido edificados con precariedad, según las posibilidades económicas de la población trabajadora.

\section{El discurso de aislamiento y distanciamiento social}

El discurso de aislamiento social obligatorio es escuchado y comprendido por la mayor parte de la población, no es una población ignorante; pero no ha sido acatado a cabalidad porque su sustento, como sabemos, depende de lo que vende cada día. Algo semejante ocurre con el distanciamiento social, ha sido comprendido, pero es traicionado por lo que denomino el lenguaje histórico corporal. Lo hemos apreciado en la primera reunión congresal, los primeros días de las presentaciones públicas del gabinete, en los supermercados, en los mercados de barrio, en las colas de los bancos; porque los cuerpos en el Perú están habituados históricamente a la proximidad como parte de la expresión afectiva de la población y también porque los espacios en los que vive, labora y se transporta la gran mayoría de la población trabajadora suelen ser lugares muy pequeños, estrechos y hacinados, entonces la proximidad es inevitable, los cuerpos están habituados a ello. En condiciones tan adversas, los habitus no son fáciles de cambiar. En muchos hogares una sola habitación hace de baño, cocina, dormitorio, comedor y carecen de un adecuado servicio sanitario. En estas condiciones es inevitable que no se guarde una cuarentena estricta y menos si las niñas y mujeres conviven con sus agresores. Si se ofreciera un eficiente servicio público de salud, de educación y transporte, con viviendas y empleos saludables para todos, la actitud sería distinta.

Lo que ha venido ocurriendo en los hospitales, en las calles, en las cárceles, el éxodo de numerosa población desempleada en las carreteras de nuestro país, la grave situación de las comunidades y pueblos de la Amazonia, la violencia de género que no ha disminuido, constituyen una tragedia que se sentía venir por las profundas desigualdades, la violencia estructural, el abandono de los derechos fundamentales, la falta de consulta previa a los pueblos indígenas, el desconocimiento de las reales condiciones de vida de la mayoría de la población y la ignorancia de las características socioculturales y ecoterritoriales de cada región.

\section{Ciudades y transporte público insalubres}

El pésimo transporte público a nivel nacional, lejos de ser un saludable servicio, afecta cada vez más la vida de la población trabajadora al movilizarla como aves enjauladas, situación que se hace insostenible, por el hacinamiento, la total incomodidad, ajena a toda condición humana, tal como ocurre incluso con el metropolitano limeño a pesar de su apariencia moderna.

Sujetos al racismo y a la ilusión de lujo y confort creado por el imaginario industrial empresarial, se gobierna a favor de la industria automotriz y la avaricia, sin importar el daño que produce al ambiente y al planeta (ergo a la especie humana y no humana) la fabricación y la circulación de millones de autos. En una familia de los sectores pudientes, hay tantos autos como los miembros que la componen, hijos y progenitores cuentan cada uno con un auto. ¿De dónde viene el caos del tránsito en el Perú?

\section{República, cuarentena, patriarcado y género}

Entre fines del siglo XIX y el siglo XX las epidemias de fiebre amarilla, tifus, peste bubónica, la tuberculosis y el cólera han sido recurrentes. En el siglo XXI, La 
tuberculosis ha rebrotado de manera muy resistente a los antibióticos, asimismo el dengue, la influenza y ahora el covid 19; siempre son los sectores populares, las poblaciones de las comunidades andinas y amazónicas las más afectadas.

La vida republicana próxima al bicentenario no ha cambiado mucho las pésimas condiciones de vida de la mayoría de la población, a pesar de que en las últimas décadas cada gobernante se vanagloriaba de estar próximos al primer mundo.

Por eso, es una impostura, pensar que la solución es exclusivamente la guerra contra el nuevo coronavirus, porque lo que está matando son las prácticas destructivas del capitalismo y el patriarcalismo, el nuevo coronavirus no es más que la creación de su propia contradicción a partir de la nefasta concepción de desarrollo en el Perú y el mundo. Lo grave es que no será la única pandemia si no se cambia drásticamente la forma de vida neoliberal y el patrón global de poder. Sabemos que los virus suelen ser de origen zoonótico, trasmitido por los animales que abandonan su hábitat cuando estos han sido destruidos por los humanos mediante las políticas extractivistas, los monocultivos y los agronegocios o por las zoonosis (Ribeiro, 2020), enfermedades infecciosas producidas por la nefasta cría industrial de animales y que son transmitidas a la especie humana.

\section{La economía del cuidado}

La economía del cuidado está constituida por todas las actividades que efectúan usualmente las mujeres en el ámbito familiar, desde la adquisición y preparación de los alimentos, el cuidado de la salud física y emocional de los miembros de la familia, la formación de los hijos, el aseo de la vivienda y todas las atenciones que requiere un hogar; todo esto puede extenderse a la economía familiar vecinal a través de la producción artesanal, las ollas comunes, la salud y las urgencias vecinales, entre otras actividades. En los ámbitos rurales comprende además el cultivo y la cosecha de los alimentos, la crianza de animales, la pesca, el tejido y las labores comunitarias compartidas con otras mujeres y varones.

Estas actividades queimplican afecto, ternura, responsabilidad y amor, no pueden parar en ninguna circunstancia. Pero para el orden social patriarcal tejido estrechamente con el capitalismo no tienen valor alguno, ya que ha sido y son asociados a prácticas exclusivamente naturales; cuando en realidad constituyen un conjunto creativo de saberes manuales, intelectuales y afectivos aprendidos durante miles de años y hoy como ayer constituyen el sostén de la familia y de la acumulación sin fin de capital. Sin el afecto y el cuidado no se reproduce la fuerza laboral ni resiste ningún orden social.

En este tiempo marcado por la pandemia, la repercusión de género en las familias es notable, ya que son las mujeres las que sobrecargan su labor con las tareas de cuidado y prevención, sin dejar de reconocer que existen varones y miembros de las comunidades disidentes que asumen la voluntad de quebrar esta desigualdad, pero son todavía muy pocos. Tampoco puede parar el cuidado sanitario, la limpieza pública y la producción agrícola, todos ellos implican atención y asistencia y suelen estar asociados a prácticas naturalmente femeninas, ¿será éste factor, además de las desigualdades socioeconómicas y el racismo, lo que incide en su desvalorización y abandono por las políticas públicas?

Cuando el gobierno emitió El Decreto Supremo Nº57-2020-PCM, que establecía días de salida diferenciados por género, con el objeto de comprar víveres o productos farmacéuticos o para la ejecución de otras actividades urgentes, generó numerosas críticas debido a la aglomeración de las mujeres, porque no contribuyó a lograr el objetivo de reducir la circulación de habitantes y aplanar así la curva de contagios. 
En el Perú, la economía del cuidado practicado sobre todo por las mujeres, contribuye a que sean ellas las que salgan a comprar en tanto temen que no se suministre bien el escaso presupuesto y porque prefieren arriesgarse ellas a poner en riesgo la vida de los miembros de su familia. Estos son algunos motivos por los cuales, los mercados de barrio y las bodegas han sido y son abarrotados sobre todo por mujeres. Los mercados populares son espacios públicos de encuentro, de intercambio emocional y de saberes, no es estrictamente un espacio solo de intercambio monetario y de valor de cambio.

Las amas de casa al ir al mercado de barrio, saborean, examinan, observan cada hortaliza, fruta o proteína que adquieren, aprecian el color, la textura, el olor, su blandura, su madurez, el brillo, su peso y precio correcto. Si se duda o no se sabe qué escoger o qué comprar, se pide ayuda y, muchas veces, antes de solicitarla, es posible que la persona que atiende y lee nuestras expresiones gestuales y corporales, pregunte por ejemplo ¿quiere frutas para el futuro?

$\mathrm{Si}$ se ignora algo culinario, se sabe que alguna de las amas de casa a las que se encuentre o la persona que atiende y sorprende muchas veces con una yapa de yerba buena, culantro y perejil, ayudarán a resolver el problema.

A través de nuestro recorrido casi frecuente por los mercados, reconfirmamos que un grupo de mujeres, en la que me incluyo, solemos comprar con prontitud, en tanto ejercemos doble y hasta triple jornada laboral. En cambio, para otras mujeres, salir del hogar durante la cuarentena, es un momento para aliviar las tensiones familiares o espaciales en casa, que se agrava sobre todo cuando se convive con agresores o cuando se cuenta con una sola habitación que hace de cocina, baño, dormitorio y comedor.

\section{Los movimientos de la sociedad y la autoridad pública social}

Las problemáticas referentes a la salud, la educación, la vivienda, el desempleo, la estructura carcelaria, entre otras, has sido constantes. En 1920, el diplomático y sociólogo Mariano H. Cornejo, en su Exposición de Motivos del Código de Procedimientos en Materia Criminal, denunciaba el hacinamiento de las cárceles convertidos en espacios intolerables y homicidas, por lo que demandó la urgencia de una reforma que pusiera término a esta deplorable situación.

En el año 1933, el médico peruano Manuel Núñez Butrón ( Arroyo, 2013), creó un sistema de atención sanitario orientado a las poblaciones indígenas y campesinas de Puno, que generó un movimiento regional al que llamó rijcharismo, palabra que viene del quechua rijchary (despierta) y que se extendió a la salud, la educación y el trabajo, fue una de las primeras experiencias de atención preventivo- promocional en el Perú adelantándose a lo que décadas más tarde se llamaría atención primaria de la salud. Núñez Butrón organizó en brigadas sanitarias, o rijcharys, a curanderos, herbolarios, exsoldados de la región, quienes iban a las comunidades a pie o en moto, para compartir prácticas de cuidado de la salud en una época de tifus y viruela. Juntos fabricaban jabones, desinfectaban habitaciones y conversaban sobre cómo prevenir las enfermedades y la importancia de la vacunación.

La propuesta de Núñez Butrón no habría tenido efectividad sin la participación efectiva de las comunidades del Altiplano.

De manera semejante podemos recordar la labor pedagógica de José María Arguedas en Sicuani, a quien no le sirvió las instrucciones monoculturales del Ministerio de Educación sino su propuesta interculturales (Ortiz, 2014), que partieron de la revalorización de los saberes y prácticas culturales propias de los pueblos de la región. 
En los asentamientos humanos y barrios populares en Lima, que surgen desde los años 40 del siglo XX, la población migrante edificó sus viviendas, las mujeres ejercieron el cuidado familiar y vecinal, formaron brigadas de salud, las ollas comunes, los comedores populares y fueron impulsoras para la creación de escuelas y las economías populares.

En la últimas décadas, las mujeres, las comunidades y los pueblos afroindoamericanos han venido resistiendo con gran intensidad las políticas de recolonización y despojo de sus territorios y exigen que las decisiones tomadas en su jurisdicción se respeten, cuestionando así la imposición de las empresas extractivas, petroleras y de monocultivos avaladas y promovidas por las instituciones del Estado que se arrogan la representación del no saber y del saber hegemónico impartido en las universidades, entre ellas, la ciencia económica, las ingenierías y las ciencias sociales. Los funcionarios y profesionales que emergen de ellas, funcionales a las corporaciones y gobiernos, desconocen la realidad de los pueblos y los pocos que la conocen las ignoran porque están sujetos al imaginario consumista, individualista y racializado, de lujo y confort explotado por el marketing neoliberal. Situación que se devela dolorosamente en este tiempo de pandemia.

Por otro lado, el feminismo popular, indígena, cholo, plebeyo, afro, indígena, en suma, comunitario vienen planteando la despatriarcalización y la descolonialidad del poder y del saber en todos los ámbitos incluso en sus propias organizaciones y es que para la descolonialidad del poder el cambio empieza en una/o misme. Esto es un gran avance, sobre todo cuando se cuestiona autocríticamente la centralidad del poder en las propias organizaciones y en las instituciones sociales. En segundo, constituye una gran esperanza cuando a las denuncias sobre acoso y violencia sexual -que son fundamentales- se suma de modo integral el cuestionamiento de la violencia estructural y sobre la Naturaleza o mejor Pachamama; en estos días de confinamiento en la región latinoamericana se ha asesinado a más de una decena de defensoras y defensores ambientales. Estas demandas y acontecimientos de muerte no pueden ser ignorados por la universidad y menos por la sociología y las ciencias sociales; existen algunos esfuerzos individuales por propiciar una visión distinta, pero no son suficientes.

Otro factor a destacar es la creación de espacios públicos de debate y pensamiento crítico que interpela por un lado la sujeción de la región a las exigencias del Banco Mundial, la OMC, OEA, etc., del capital transnacional; y, por el otro, la sujeción de las mujeres a través del feminismo liberal que al demandar la igualdad con los parámetros del orden social patriarcal capitalista no cuestiona el orden social patriarcal ni la colonialidad del poder ni el extractivismo. Este intenso debate viene ocurriendo sobre todo en Chile, Argentina, Bolivia y también en Perú. Por otro lado se denuncia que los gobiernos y entidades internacionales hacen lo posible de coaptar a dirigentes indígenas y populares. En el siglo XIX, la autora de la Unión Obrera, propuso la urgencia de la organización autónoma de las obreras y obreros (Tristán, 2018), estas no debían sujetarse ni al estado ni a las corporaciones, sino mas bien-como más tarde lo sostuvo el autor de la perspectiva de la colonialidad del poder-fortalecer su carácter de autoridad privado social (Quijano, 1988), de manera semejante a las comunidades amazónicas que asumen y exigen se respete la autogestión y autonomía de sus pueblos.

Hoy, en varias regiones del país, la población trabajadora está recurriendo al trueque y afrontando la pandemia mediante la organización comunitaria a través de las rondas campesinas sobretodo en la región de Cajamarca. Numerosos jóvenes se reúnen en pequeñas unidades artesanales de manera cooperativa o comunitaria, en los barrios se reabren las ollas comunes y la creación de biohuertos comunitarios; asimismo se gestan Gobiernos Autónomos como el Wampis que vienen fortaleciendo 
sus principios y valores de convivencia comunitaria a fin de defender su derecho a la libre determinación para lograr el Tarimat Pujut / Vida Plena.

Estas son algunas prácticas de lo que se denomina economía del cuidado y del Bien vivir que se basan en la ayuda mutua, la reciprocidad, el respeto a la Madre Tierra, son relaciones sociales existentes que suelen pasar desapercibidas cuando en realidad son el sostén de nuestros pueblos, no todo es corrupción y egoísmo.

\section{Post pandemia, la descolonialidad del poder y la autoridad pública social}

Sentipensar el poder desde la descolonialidad del poder feminista, desde los pueblos y nacionalidades indígenas y la población trabajadora, en estos tiempos de pandemia, supone interrogarse sobre la radical redistribución del poder y las relaciones se autoridad en toda instancia, sea en el ámbito privado o público, en las relaciones micro y macrosociales y en comprender que nada de lo que ocurra al individuo es ajeno a lo que ocurra en el globo.

Sabemos que en el mundo, el patrón global de poder propiciará mediante la conectividad digital de alta velocidad que nuestros hogares no sean nunca más espacios exclusivamente personales, ni tampoco las escuelas ni las fábricas ni los centros de salud.

En China y los Estados Unidos, las elites de poder están presionando por conseguir estados policiales digitales como modelos de control (Han, 2020) (Klein, 2020). Klein sostiene que el gobierno norteamericano y la gubernamentalidad global tienen el interés de reconfigurar la sociedad post covid, integrando la tecnología a todos los campos de la vida a través, por ejemplo, del control de Google Eric Schmidt. Añade que la compañía Anuja Sonalker CEO de Steer Tech, con sede en Maryland, vende tecnología de estacionamiento propio y que uno de sus funcionarios, en un reciente discurso, aseveró que su compañía da prevalencia al uso de tecnología sin contacto y sin humanos, en tanto: "Los humanos son biopeligrosos, las máquinas no lo son" (Klein, 2020).

La vigilancia digital autoritaria tiende a acrecentarse y puede tornarse en totalitaria. En el Perú, nuestras casas, desde antes de la pandemia, se están convirtiendo en espacios de trabajo que nunca concluyen, se continúa laborando los fines de semana y feriados. Las exigencias laborales y de supervivencia son cada vez más duras, sobre todo porque con esta forma de trabajo y el teletrabajo las grandes compañías ahorran costos laborales, acrecentando así la precarización del trabajo. Por lo que el control de la sociedad, como bien lo expresa Klein, tiende a acelerarse a una velocidad warp. Por suerte, desde la sociología, sabemos que si bien las estructuras sociales históricamente conformadas obedecen a las relaciones y complejas estructuras de poder que constriñen a los individuos, en tanto actores, performers, agentes, podemos lograr cambios y transformaciones drásticas.

Si entendemos que el ser humano, en su constante siendo o devenir, es una relación ecosocial, psíquica e intersubjetiva, supone que lo que suceda en la intimidad o el individuo no es algo aislado del orden social global ni del territorio que habita ni de la estructura económica y patriarcal interdependientes históricamente de la acumulación sin fin del capitalismo en un espacio y tiempo.

Desinteresarse de este profundo y complejo tejido ecosocial nos puede dar grandes sorpresas, por ejemplo que a pesar de las políticas públicas de género en diversos lugares del mundo, continúe y hasta se incremente la violencia, los feminicidios, los suicidios o que ingrese a las escuelas el fundamentalismo religioso, que se destruya el ecosistema que habitamos sin que nos demos cuenta y que las plagas y pandemias, los alimentos transgénicos arrasen con la vida, mientras que los medios y las redes virtuales propagan una sociedad en la que reina ilusoriamente la libertad de elegir 
basada en la felicidad efímera del consumismo y en el "me gusta", como sostén del autoritarismo del modelo económico vigente.

Lo novedoso en los últimos movimientos de la sociedad es que al interior de ellos sobre todo en Chile, Ecuador, Bolivia y en Perú, aún en menor proporción, se aprecia una dinámica que busca, además de la descolonialidad del poder, propiciar otras relaciones de autoridad, basada en la horizontalidad y la organización comunitaria. No hay una elite, un líder o lideresa que dirija a un pueblo que considera ignorante. La despatriarcalización del poder y la democratización radical empieza a hacerse realidad.

Es esta dinámica, es imprescindible preguntarse por qué en el Perú las organizaciones sociales son muy frágiles. Si sabemos que más del 70 \% de la población forma parte de la mano de obra marginalizada y que ésta es sumamente heterogénea, no podemos hablar de un movimiento indígena o de un movimiento feminista, sino mas bien de movimientos de la sociedad con diversos intereses comunes y no comunes en el ámbito del trabajo. Por eso la fuerza indígena y la feminista son estructural e históricamente heterogéneas en nuestra Afroindomérica ${ }^{3}$ /Abya Yala, ya que están atravesadas por las clasificaciones sociales de género, racializadas, territoriales, socioeconómicas y culturales. Además, los gobiernos de derecha e izquierda usualmente han contribuido y contribuyen corporativamente a desarticular las organizaciones sociales. El Perú no es ajeno a esto, se hizo durante el gobierno de Velasco, García, el fujimontesinismo y los gobiernos sucesivos de la derecha, Toledo creó paralelamente entidades indígenas y desde las corporaciones y financieras se apoya la lucha exclusiva contra el acoso, soslayando el orden social patriarcal capitalista. El reto es cómo articular la heterogeneidad a nivel local, regional y global.

La población originaria es también heterogénea, un sector se autoidentifica como indígena, otro como campesina. Un sector es evangélico y pertenece al sector agrícola, otro al pequeño y mediano comercio, Otro forma parte de la mano de obra ocasional, marginalizada o polo marginal de la economía (Quijano, 1996), otro sector forma parte del sector asalariado y minero. Vale señalar que la intelectualidad indígena suele no estar separada del trabajo manual y esto es de gran importancia destacar, necesitamos recuperar la unidad del trabajo manual e intelectual; su separación ha sido y es realmente trágica como lo planteó la gran Mercedes Cabello a fines del siglo XIX. Pensar que unos realizan el trabajo manual y otros el trabajo intelectual constituye una relación colonial, racista y patriarcal.

En el movimiento indígena y feminista boliviano, histórica y socialmente heterogéneo, como lo es en la región, existe la organización de las pequeñas productoras que integran la Confederación Sindical de Mujeres Interculturales, que reúne a un millón de productoras, a profesionales y estudiantes. Los gremios de comerciantes de El Alto también están organizados.

En las actuales circunstancias de pandemia global, el temor, la militarización y la vigilancia autoritaria parecen no paralizar a estos movimientos. Vienen surgiendo debates regionales virtuales, amotinamientos en las cárceles clamando por la defensa de la vida y los derechos fundamentales de los presos y trabajadores, manifestaciones de protesta de las enfermeras y del personal sanitario en Iquitos, en Lambayeque, en Piura y en diferentes regiones del país reclamando equipos, oxígeno, agua y medicinas; las demandas del personal de limpieza exigiendo equipos de protección; trabajadores mineros reclamando por su salud; miles de trabajadores volviendo a sus lugares de origen, todo esto sumado a la precariedad del empleo, a la creciente población que no acata la cuarentena sobre todo en los barrios y el sector que supervive mediante la economía economía popular, parecen derrumbar el mito del

3 Mariátegui usó el concepto de Indoamérica a fin de visibilizar a los pueblos originarios, propongo Afroindoamérica en reconocimiento y visibilización de la población afrodescendiente. 
emprendedurismo y la ideología del exitismo neoliberal y da cuenta de la crisis del estado, de su inoperancia a pesar de las buenas intenciones de varios de sus miembros, da cuenta de lo que parece ser el derrumbe del desarrollismo neoliberal, ergo del tiempo lineal y progresivo de la modernidad y su razón genocida. La democracia representativa como régimen del patrón global de poder - que emergió y comenzó a institucionalizarse con la monarquía patriarcal en Occidente-, está en profunda crisis y el lugar del estado vuelve al debate.

Los pueblos en movimiento en Perú y en varias regiones de nuestra Afroindomérica afronta la pandemia mediante las ollas comunes con la solidaridad de numerosos personas y colectivos, con la creación de biohuertos a nivel familiar y vecinal, el trueque en las comunidades de los Andes, las ferias de alimentos de los pequeños productores, las rondas campesinas en la región de Cajamarca; revelando y reafirmando la autogestión de las comunidades populares.

Una experiencia novedosa, antes de la pandemia, que no solo cuestiona la democracia representativa sino que promueve prácticas alternativas de organización, gobierno y autoridad, en tanto cuestiona la reconcentración de poder en un individuo o elite y la verticalidad -meollo del patriarcado capitalista-, radica en los cabildos en la reciente experiencia afroindoamericana.

Un cabildo reúne a integrantes de una comunidad, a organizaciones o asociaciones sociales y vecinales, con el objeto de debatir y canalizar demandas. Son espacios de deliberación que, en el mejor de los casos, promueven la radicalización de la democracia, la desconcentración del poder, la producción de conocimientos como un proceso dialógico y colaborativo. Se ha llevado a cabo en los barrios, en las plazas, en los colegios, las universidades; hay también cabildos culturales y artísticos, todos invitan a la reflexión. En las manifestaciones efectuadas en Chile durante el 2019, miles participaron en ellos, sus integrantes son personas de toda edad, género y pensamiento ideológico, se reunieron para debatir sobre las salidas a la crisis. Con el aislamiento social que se establecerá por buen tiempo y la tendencia a la militarización ¿será posible que se mantengan y fortalezcan?

Desde la producción sociológica en Chile, se afirma que históricamente los cabildos guardan debilidad debido a que su funcionamiento suele ser capturado y normado por los grupos de poder y el estado (Avendaño, 2019). El gobierno de Piñera, por ejemplo, emitió normas que dan instrucciones de cómo organizar cabildos y de como enviar los petitorios; con todo, el debate continúa, un sector del movimiento fortalece su carácter de autoridad privada social de modo equivalente a las comunidades andinas y a las Rondas Campesinas; por lo que consideramos que la convergencia de este tipo de organizaciones podrían articular una autoridad pública social y no estatal (Quijano, 1988), a nivel local, regional y global. En ese sentido, resulta vigente la propuesta de Flora Tristan, las organizaciones sociales no deben sujetarse ni al mercado ni al estado.

¿Cómo evitar la domesticación o sujeción de estos movimientos a los requerimientos del estado patriarcal y de las corporaciones? La respuesta viene de los propios movimientos. Una participanteen elúltimo congreso dela Asociación Latinoamericana de Sociología manifestó que en su país acababan de formar una red de sociólogas con las pautas dadas por el estado, pero como ellas están claras de que seguirlas sería reproducir las prácticas de gobierno y autoridad patriarcal, así como sus esquemas de organización y percepción, de manera interna contravienen sus esquemas al organizarse horizontalmente sin una cabeza que lo sabe todo.

Estas prácticas novedosas sumadas a la organización y la autoridad comunitaria, la reciprocidad, la ayuda mutua y la alegría del trabajo colectivo, de las comunidades andinas y amazónicas con conflictos evidentes por el individualismo, consumismo 
y patriarcalismo apabullante, así como la recuperación de las lenguas originarias, la revalorización de los saberes, de los patrones de expresión, valoración y comunicación propias abiertas a dialogar con el mundo, constituyen propuestas alternativas. La autoridad comunitaria obedece y rinde cuentas a las comuneras y comuneros, los cargos son rotativos y no eternos; de esta manera configuran una democracia de mayor intensidad. Además, los valores comunitarios mencionados han sido muy valiosos en el proceso de urbanización y construcción de las ciudades en Perú, en los mecanismos de supervivencia a través de las unidades económico populares y artesanales, lo cual no niega los conflictos que también se presentan.

Por otro lado, es muy significativa la reoriginalización cultural en todas las áreas del saber, sobre todo en el mundo de las artes, que en estos tiempos de pandemia, de tendencia a la militarización, al autoritarismo, de ahondamiento de la crisis a todo nivel no se ha detenido. Se espera que las organizaciones de estos movimientos se fortalezcan con el objeto no solo de afrontar este duro periodo sino de contribuir en la búsqueda común de otros patrones de convivencia y de otros horizontes de sentido.

Es pertinente no perder de vista que los estados modernos están sujetos al patrón global de poder y al fundamentalismo del mercado, pero en tiempos de riesgo admiten que el estado se abra como ente regulador y como emisor de políticas sociales, puede incluso estatizar empresas que se declaran en quiebra y una vez recuperadas con la tributación de toda la población trabajadora retornar a su estado de privilegio. Se admite al estado como un ente de salvataje pero no como emisor de políticas públicas duraderas que desconcentren y redistribuyan la riqueza y el poder. La crítica al estado tendría que diferenciarse de la visión de los progresismos y de la crítica neoliberal ya que este, por ejemplo, de un lado defiende la supuesta mano invisible del mercado y por el otro promueve que el estado proteja sus intereses. El privado capitalista y lo estatal capitalista son dos caras de la misma moneda (Quijano, 1988).

Es también muy significativo, que en varias regiones de los Estados Unidos, en Minnesota, por ejemplo, se haya derribado la estatua de Colón, símbolo de colonialismo y colonialidad, de genocidio, esclavitud y etnocidio, símbolo del orden social patriarcal que se globalizó desde hace mas de 500 años. En Temuco, Chile, se ha derribado la estatua de Arturo Prat, en Concepción la imagen de Pedro de Valdivia, a quien se considera el padre fundador de Chile. La caída provocó la algarabía de cientos de personas que entonaron consignas en mapudungun. Esta acción colectiva expresa el cuestionamiento a los valores dominantes que se transmiten en los espacios públicos y, al mismo tiempo, el cuestionamiento de los usos coloniales, racializados y patriarcales de dichos espacios. El protagonismo de la bandera Mapuche en el estallido social en Chile, de las mujeres, liderezas y pueblos indígenas en toda nuestra América así como la circulación de miles de trabajadores en Perú volviendo a sus lugares de origen expresan que son tiempos otros.

\section{Conclusiones preliminares}

Lo que ha venido ocurriendo en las calles, en los medios de transporte, en los mercados, en las cárceles, en los centros de salud, en los hogares, el retorno de la población a sus lugares de origen, el doloroso alto índice de mortandad, la grave situación de las comunidades y pueblos de la Amazonia, el incremento de la violencia de género, constituyen una tragedia que se sentía venir por las profundas desigualdades, la violencia estructural acentuada por el neoliberalismo vigente, el orden social patriarcal y el patrón global de poder teñidos de racismo, que se traducen en el abandono de los derechos humanos fundamentales, el desconocimiento de las reales condiciones de vida de la mayoría de la población, la ignorancia de la heterogeneidad sociocultural y ecoterritorial de cada región, que obedece -entre 
otros aspectos- a la formación eminentemente eurocéntrica de los profesionales y funcionarios en las universidades del país.

Ante estos vacíos, en numerosos casos, como ha ocurrido a lo largo de la historia de los pueblos en Perú y en nuestra América, la población organizada viene afrontando la crisis sanitaria, agravada con el incremento del desempleo y sus repercusiones en la vida cotidiana, mediante la solidaridad, la reciprocidad y el ayni, a través de los comedores populares, las rondas campesinas, los colectivos solidarios. Es así que surgen alternativas que nacen de las organizaciones sociales y los movimientos de la sociedad que abren la posibilidad de conformar una articulada autoridad pública social; como lo vienen haciendo las asambleas regionales por la Amazonía, los cabildos en Chile, entre otros.

Por otro lado, desde las élites, con el discurso de la reactivación económica se contribuye a ahondar la precarización del trabajo, el incremento de la mano de obra marginalizada y la creciente vigilancia autoritaria, como parte de la política global, la militarización y el autoritarismo.

Estos acontecimientos cuestionan los mitos de emprendedurismo y desarrollismo neoliberal, ergo el tiempo lineal y progresivo de la modernidad y su razón genocida. La democracia representativa como régimen del patrón global de poder se agrieta profundamente. Las fuerzas en movimiento parecen conducir a una mutación radical.

Por todo lo indicado, que corresponde a este momento, para nada definitivo ni acabado, es posible considerar que nuestra América / Abya Yala y el mundo está siendo remecida por un pachacuti, porque ante el develamiento y cuestionamiento que viene ocurriendo de la red compleja global del poder en su dimensión socioeconómica, racializada, epistémica, biopolítica y patriarcal; la pandemia global vino como anillo al dedo para propiciar la vigilancia totalitaria que se propone profundizar el control de los cuerpos humanos y no humanos.

Ahora bien, dado que la vida está en juego, los movimientos de los pueblos, de la sociedad y de la propia Madre Tierra, parecen decir que es un tiempo otro, el tiempo de los agraviados y ofendidos durante más de 500 años y anuncian la posibilidad de otros tipos de organización y autoridad, entre ellos la emergencia de asociaciones y colectivos con autoridades públicas sociales desconcentradas, es decir despatriarcalizadas, que respetan la individualidad y promueven el afecto, la reciprocidad, el cuidado mutuo y de la Pachamama en la producción y la reproducción de la vida.

Son prácticas que no son una utopía paradisíaca en tanto provienen de los saberes y prácticas de las mujeres y los pueblos indígenas que han quedado subalternizadas por el tiempo lineal del supuesto progreso indefinido y la explotación sin fin de los humanos y de los bienes comunes, que no niegan los conflictos que también arraigan y que retan a explorar cómo convivir en la heterogeneidad.

El tiempo lineal y progresivo del patrón global de poder, que en nombre del desarrollo y la felicidad efímera del consumismo, destruye aparatosamente la vida, parece derrumbarse; aunque todo depende de lo que hagamos o dejemos de hacer.

\section{Referencias Bibliográficas}

Arendt, H. (2011). Los orígenes del totalitarismo, Madrid, Alianza Editorial.

Arguedas, JM. (2011) Nosotros los maestros. Selección estudio preliminar y notas de Wilfredo Kapsoli Escudero, Lima, Editorial Horizonte y Derrama Magisterial.

Arroyo, H. (2013). Runa soncco: Manuel Núñez Butron y su proyecto de educación sanitaria, Revista Peruana de Medicina Experimental y Salud Pública, Lima, Vol 30 (2). Disponible en: https://rpmesp.ins.gob.pe/index.php/rpmesp/article/view/215/2351 . 
Austin, J. (1970). Quand dire c'est faire, Paris, Le Seuil.

Avendaño, O. (2019). Cabildos populares en Chile: talleres para un nuevo país, en DW Made for minds. Disponible en: https://www.dw.com/es/cabildos-populares-en-chile-tallerespara-un-nuevo-pa\%C3\%ADs/a-51158577 Consultado el 20.05.2020.

Han, B. (2020). La emergencia viral y el mundo de mañana. Byung-Chul Han, el filósofo surcoreano que piensa desde Berlín, El País, 22.03. Disponible en: https://elpais.com/ ideas/2020-03-21/la-emergencia-viral-y-el-mundo-de-manana-byung-chul-han-elfilosofo-surcoreano-que-piensa-desde-berlin.html Consultado el 30.04.2020.

Cabello, M. (2001) El conspirador. Autobiografía de un hombre público. Lima, Kavia Cobaya Editores.

Cornejo, M. (1920). Exposición de Motivos del Código de Procedimientos en Materia Criminal, Novísimo Código de Procedimientos en materia Criminal, Lima, Imp. Torres Aguirre

Decreto Supremo (2020). Declara Estado de Emergencia Nacional por las graves circunstancias que afectan la vida de la Nación a consecuencia del brote del COVID-19, El Peruano. Diario oficial del Bicentenario. N ${ }^{o}$ 044-2020-PCM, 15.03.2020, pp. 11-13. Disponible en: https:// busquedas.elperuano.pe/normaslegales/decreto-supremo-que-declara-estado-deemergencia-nacional-po-decreto-supremo-n-044-2020-pcm-1864948-2/ Consultado: el 19.05.2020.

INEI. (2020). Empleo disminuyó 25\% en Lima Metropolitana en el trimestre febrero-marzoabril del 2020, Portal INEI. Disponible en: https://www.inei.gob.pe/prensa/noticias/ empleo-disminuyo-25-en-lima-metropolitana-en-el-trimestre-febrero-marzo-abrildel-2020-12188/ Consultado el 15/05/2020

Klein, N. (2020). Screen new deal. Under Cover of Mass Death, Andrew Cuomo Calls in the Billionaires to Build a High-Tech Dystopia, en The Intercept, 8.05.2020. Disponible en: https://theintercept.com/2020/05/08/andrew-cuomo-eric-schmidt-coronavirus-techshock-doctrine/ Consultado el 15.05.2020.

Ortiz, C. (2020). Nuestra América / Abya Yala "está siendo sacudida por un Pachacuti", en Servindi. Comunicación intercultural para un mundo más humano y diverso. Disponible en: $\quad$ https://www.servindi.org/30/01/2020/la-crisis-del-patriarcado-capitalistacomunalidad-y-la-descolonialidad-del-poder

Ortiz, C. (2004). Procesos de descolonización del imaginario y del conocimiento en América latina. Poéticas de la violencia y de la crisis. Lima, Fondo Editorial de la Facultad de Ciencias Sociales de la UNMSM.

Ortiz , C. (2016). Bagua y el Perú. Dominación patriarcal y comunalidad. Lima, Revista de Sociología, Fac. de Ciencias Sociales de la UNMSM, (Lima) 26, pp. 91-124.

Ortiz, C. (2011). José María Arguedas y la educación. Una aproximación, Presentación del libro José María Arguedas Nosotros los maestros. Selección preliminar y nota de Wilfredo Kapsoli. Lima, Derrama Magisterial, 12 de octubre.

Ortiz, C. (2014). José María Arguedas y la educación. Una aproximación, Yuyaykusun, Revista del Departamento Académico de Humanidades de la Universidad Ricardo Palma, Nro.6 pp. 15-30. Disponible en: http://revistas.urp.edu.pe/index.php/Yuyaykusun/article/ view/219/206

Ortiz, C. (2009). Felipe Guaman Poma de Ayala, Clorinda Matto de Turner, Trinidad Henríquez y la teoría crítica. Sus legados a la teoría social contemporánea, Yuyaykusun. Revista del Departamento Académico de Humanidades de la Universidad Ricardo Palma, Nro.2, pp. 263-284.

Quijano, A. (1996). La economía popular y sus caminos en América Latina, Lima, Horizonte.

Quijano, A. (1988). Modernidad, identidad y utopía en América Latina, Lima, Sociedad y Política.

Ribeiro, S. (2020). Ecología política de las pandemias. Tercer encuentro: Luchas y horizontes ecocomunitarios en tiempos pos-covid. CLACSO TV. Conversatorio 07.05.2020. Disponible en: https://www.youtube.com/watch?time_continue $=11 \& v=4 i 6 R i \_r n e o w \& f e a t u r e=e m b$ title 
Tristán, F. (2018). Unión obrera. México PRD.

Vizcarra, M. (2020). Spots publicitarios, TV Perú. 